\title{
ENTREVISTA A LA ABOG. VANESSA THORSEN ORREGO REALIZADA EN EL PRE CONGRESO INSTERDISCIPLINARIO DE LA FAMILIA E INFANCIA - UNIFÉ: “VIOLENCIA CONTRA LOS NIÑOS, NIÑAS Y ADOLESCENTES CON DISCAPACIDAD” (27 Y 28 DE AGOSTO DE 2019) -
}

\section{“EL VALOR DE UNA EXPERIENCIA"}

\author{
Por: Abog. Úrsula Vilma Bazán Dubbertin
}

\begin{abstract}
INTERVIEW TO LAWYER: VANESSA THORSEN ORREGO HELD AT UNIFE PRE-INSTERDISCIPLINARY CONGRESS OF FAMILY AND CHILDHOOD: "VIOLENCE AGAINST CHILDREN AND ADOLESCENTS WITH
\end{abstract}

DISABILITIES" (27 AND 28 AUGUST 2019)

\author{
"THE VALUE OF AN EXPERIENCE" \\ By: Ursula Vilma Bazán Dubbertin, Lawyer.
}

\section{Maestra de Ceremonias: Abog. Gisela Vidal}

Seguidamente, damos inicio a la sesión "El valor de una experiencia", un espacio donde conoceremos que la discapacidad no son limitaciones y tampoco pretextos cuando el ser humano se plantea objetivos en la vida.

En ese sentido, nos complace presentar a la abogada Vanessa Thorsen, egresada y titulada por la Universidad Femenina del Sagrado Corazón.

Vanessa también es egresada de la Maestría en Derecho con Mención en Derecho Constitucional de la Pontificia Universidad Católica del Perú, egresada del Diplomado en Derecho Administrativo y Gestión Pública del Centro de Altos Estudios Nacionales, y cuenta con 20 años de prestación de servicios a entidades públicas como la Defensoría del Pueblo, y el RENIEC. Actualmente, labora en el OSIPTEL, en el ámbito de políticas públicas y en el desarrollo para los sectores de la población en situación de vulnerabilidad y excluidas.

Cabe resaltar que Vanessa Thorsen fue comisionada en el Equipo de Defensa de los Derechos de las Personas con Discapacidad de la Defensoría del Pueblo. Actualmente, se desempeña como vocal del Tribunal Administrativo de Solución de Reclamaciones de OPSITEL. Entre los reconocimientos obtenidos podemos destacar su condecoración: 
"Orden al mérito de la mujer" en la categoría: ejemplo de superación en las adversidades, otorgado por el Ministerio de la Mujer y Poblaciones Vulnerables en el año 2015.

Vanessa Thorsen será entrevistada por la abogada Úrsula Bazán, quien es estudiante de la Maestría de Derecho Civil con mención en Derecho de Familia y Derecho Procesal Civil.

\section{ENTREVISTA:}

\section{Abog. Úrsula Bazán:}

Muchas gracias ante todo, agradecer a la Dra. Olga María Castro Pérez Treviño y al decano por esta actividad. No solamente es participar de este congreso, sino de haberme brindado el gusto y el privilegio de entrevistar a Vanessa, una persona que salió adelante en el ámbito de su formación académica, con logros y reconocimientos tanto académicos como laborales. Asimismo, es una mujer feliz, y creo que sería una frase para poder resumir y unir lo que pude apreciar de Vanessa: "una mujer feliz".

\section{Abog. Vanessa Thorsen:}

Hola, muy buenas noches es para mí un honor estar acá en mi casa de estudios como dijo Gisela, yo soy egresada de UNIFÉ y vine a conversar con ustedes un poquito sobre mi experiencia: ¿qué significa ser una persona con discapacidad?.

\section{Abog. Úrsula Bazán:}

Vanessa, conversamos hace unos días respecto a la dinámica de esta entrevista, que iba a ser un poquito diferente a las exposiciones que se han podido escuchar en este congreso. Y conversábamos también acerca de cómo fue tu vida al inicio de tus estudios. Quisiera que compartas con los presentes, si tu haz sentido que tu derecho a la educación ha estado garantizado desde el principio a plenitud.

\section{Abog. Vanessa Thorsen:}

Primero quiero aquí resaltar algunos puntos muy importantes que se han abordado en las conferencias que nos han precedido. Uno de ellos es la importancia del "rol de la familia" y la importancia de implementar 
programas de orientación y asistencia. Cuando yo nací hace unos poquitos años, como hace 44 años, puedo decir que el enfoque de la temática de discapacidad era absolutamente diferente.

Entonces, mis padres se enfrentaron a una discapacidad. Nadie les dijo qué cosa podían hacer, a donde ir y cómo. Pero ellos tuvieron el inicio y el compromiso de: "bueno ... nos tocó una niña con discapacidad y tenemos que seguir adelante." Primero, la educación especial que recibí en el colegio Inmaculada de Barranco donde compartí un ambiente de estudios con personas con discapacidad visual y personas con discapacidad auditiva; y yo traviesa me pasaba al patio de los chicos con discapacidad auditiva ... (risas). Luego asistí al colegio San Francisco de Asís en Surco, un colegio especial para niños con discapacidad visual, y así se acabó la etapa primaria. "¿Y después? ¿Qué vamos hacer?" se preguntaron mis padres: ... "buscar un colegio que te brinde una educación integral". A diferencia de antes, actualmente contamos con un marco normativo de protección y promoción de la educación inclusiva, tenemos servicios de asistencia que atienden a las necesidades educativas como los programas del Ministerio de Educación que años atrás no existían.

Bueno, me quedé en la búsqueda de un colegio. Les cuento las experiencias que tuve de colegios particulares reconocidos y también de colegios religiosos que me dijeron que ${ }_{i} N O$ ! Me cerraron las puertas. Entonces estudie en el Colegio Sagrado Corazón y Sofía de Fátima que con una visión humanista y moderna siguiendo el derecho y las enseñanzas de Mater, este centro educativo aceptaba a esta población. Cuando ingresé me hicieron una gráfica bonita para ver cómo será mi ingreso, mi relación con las chicas, de cómo íbamos a interactuar y fue una experiencia muy bonita. El colegio demostró compromiso, que asumió al tener a una persona con discapacidad y asumió de cómo tu discapacidad pasa a un segundo plano, respetando primordialmente el derecho a la educación y el derecho al desarrollo que tiene una persona como ser humano. Digamos que primero es el ser humano y luego la condición de discapacidad. Viví una experiencia muy bonita y se formó un grupo de compañeras bastante fraterno y la ley de la vida académica.

\section{Abog. Úrsula Bazán:}

Justamente de las exposiciones que podemos escuchar, se precisaba que los estudiantes, niñas, niños y adolescentes con discapacidad eran susceptibles de ser víctimas de violencia, acoso sexual; sin embargo, eso no fue tu caso. 


\section{Abog. Vanessa Thorsen:}

Yo creo que también es un tema de cuestión de enfoque de vida. Por ejemplo, si yo iba a un sitio, yo era muy tardona pero entraba diciendo ¡hello chicas, buenas noches! .... digamos que uno tiene que aprender a tomar la vida como un bien, de cada experiencia que uno tiene debe buscarle un lado positivo, y uno siempre tiene que tomar las cosas con un buen humor en lugar de exponerte que te hagan bullying para que los efectos negativos sean mucho menores.

\section{Abog. Úrsula Bazán:}

Tú tuviste la oportunidad de acceder a un colegio que estuvo a la vanguardia de lo que es acoger a un estudiante con discapacidad porque no existía esa cultura inclusiva en ese momento. Tú y yo tenemos la misma edad, pero ¿consideras que en general los centros educativos o las instituciones educativas superiores están en este momento preparados para garantizar el derecho a la educación de las personas con discapacidad?

\section{Abog. Vanessa Thorsen:}

Bueno, definitivamente tienen que estarlo. Tenemos un marco normativo que viene desde la convención Internacional de los Derechos de las personas con discapacidad, la Convención Americana, la legislación nacional y todos los dispositivos normativos que establecen las condiciones de adaptabilidad que deben tener los centros de educación, incluso la propia Ley General de las personas con discapacidad; establecen vacantes especiales en los exámenes de acceso en los servicios universitarios a personas con discapacidad, establece también las condiciones de accesibilidad y de acondicionamiento que deben tener las universidades para atender necesidades educativas a los estudiantes con algún tipo de discapacidad.

Aquí, por ejemplo, debo resaltar que la UNIFÉ tuvo la capacidad en la época que era estudiante. Yo no sé si fue una política específica en esa época, pero éramos como 2 o 3 personas con discapacidad, chicas de otras facultades nos hablaban y nos decían ¡hola! ¿Te puedo ayudar? Ya sea en la lectura, en la búsqueda de libros ya que estas señoritas tenían un programa que consistía en identificar a las personas que tienen una discapacidad en la universidad y que necesitan de repente un apoyo y me pareció genial. Yo decía: “¡Chicas se llevan mis separatas y lo graban en casette!" Ya que todavía en esa época no existían los aparatos tecnológicos que tenemos ahora, como detectores de pantalla o asistencia de voz. 


\section{Abog. Úrsula Bazán:}

Sin embargo, ¿consideras que en efecto tenemos leyes para salvaguardar los derechos y el ejercicio de los derechos de las personas con discapacidad, pero que en la práctica esto se materializa?

\section{Abog. Vanessa Thorsen:}

De repente no en la dimensión adecuada pero no depende de las universidades y los centros de educación, sino de las propias personas con discapacidad que deben estar empoderadas de conocimiento de sus derechos y demandar el cumplimiento de las obligaciones que tienen las instituciones. Las personas con discapacidad tenemos que hacer que este marco normativo esté vivo y vigente.

\section{Abog. Úrsula Bazán:}

Asimismo, ahora que laboras en OPSITEL me mencionaste que las empresas que prestan sus servicios de telecomunicaciones están obligadas a emitir los recibos en sistema Braille a las personas que tienen discapacidad visual.

\section{Abog. Vanessa Thorsen:}

Si, bueno... yo también tuve la suerte que todas las instituciones públicas en las que he trabajado, tanto en la Defensoría del Pueblo y el OSIPTEL, siempre las autoridades han tenido una visión bastante positiva del tema de discapacidad y el interés de implementación de las políticas públicas para promover la inclusión de las personas con discapacidad y el ejercicio en sus derechos en plano de igualdad.

Efectivamente, el OSIPTEL ha emitido una norma de condiciones de uso de servicios públicos de telecomunicaciones que contiene beneficios específicos para las personas con discapacidad:

El primero relativo a la accesibilidad en la página web, pues la Ley General de Personas con Discapacidad establece este beneficio y que a su vez obliga a éstas empresas o instituciones públicas a contar con una página web accesible. OSIPTEL ha establecido esta aplicación también para las empresas operadoras que prestan servicios públicos en telecomunicaciones y sus páginas web deben tener aplicativos y sistemas que permitan a una persona con discapacidad la navegación de manera autónoma - de ser el caso, es decir, en las mismas condiciones que los demás, para acceder a los contratos, promociones y otros beneficios que ofrecen a sus usuarios o clientes. 
Siempre he tenido la oportunidad de poder acceder a recibos en sistema braille con los mismos contenidos y características de aquellos que se remiten a cualquier usuario.

\section{Abog. Úrsula Bazán:}

Incluso me comentabas que una persona que no tenía ninguna discapacidad visual llego a recibir un recibo en braille.

\section{Abog. Vanessa Thorsen:}

$\mathrm{Si}$, precisamente a manera de anécdota, hace unas semanas me llamaron de la oficina y me dicen:

*Doctora queremos su ayuda.

YO: ¿Qué pasó?

*Lo que pasa es que tenemos a un ciudadano que ha recibido un documento en braille y el ciudadano no entiende qué es lo que le indican en este documento, no sabe si es una resolución del tribunal, o recibo, ¿usted podría bajar?.

YO: Si, perfecto! (Bajo y lo que había recibido el usuario era un recibo de telecomunicaciones). Qué alivio.

Entonces pensemos siempre que todo lo que hagamos sea útil para cada tipo de público que integra nuestra sociedad.

\section{Abog. Úrsula Bazán:}

Justo a ese punto quería llegar, ¿consideras Vanessa que la sociedad es consciente de la necesidad de establecer mecanismos en general de inclusión que pueda facilitar la vida diaria de las personas con discapacidad?

\section{Abog. Vanessa Thorsen:}

Yo creo que estamos avanzando hacia eso, y creo que uno de los pasos más importantes que tenemos que dar es cambiar el "chip", es decir, dejar de ver a la persona con discapacidad “iDios mío, pobrecito!”, “¡Que penita que no habla!", “Qué paso con sus piernitas?". O sea, veamos a las personas con discapacidad como PERSONAS, por eso la ley que regula esta materia 
se denomina "Ley General de las Personas con Discapacidad" ya no es la declaración del incapaz, o los derechos de los niños inválidos o minusválidos. Se habla actualmente de personas con discapacidad o con habilidades diferentes.

Primero debemos tener presente que prevalece la condición de persona, de ser humano que tiene dignidad, así como el derecho a ser respetados y promovidos por encima de la condición de discapacidad que al final termina siendo una particularidad como lo es el "gordito", "chato", "alto", bueno todos tenemos una característica dependiente que nos permite desarrollar ciertas capacidades o habilidades, unas más que otras.

Limitarse a puertas demasiadas estrechas que no solo afecta a los que no ven, no oyen sino a los que tienen cuerpos caribeños. A lo mejor los tomacorrientes que están en la parte de arriba no son útiles para los que tienen mediana o baja estatura y de repente si se colocan a una altura mediana, los pequeños pueden acceder de manera autónoma al encendido de la luz. Por eso, siempre pensemos o diseñemos las estrategias en función al entorno y necesidad de todas las personas, con un sentido de universalidad, que facilite a cada colectivo que integra nuestra sociedad, el disfrute de todos los bienes y servicios.

\section{Abog. Úrsula Bazán:}

Justamente de eso, también hablamos que algún momento, a lo largo de nuestra vida podemos tener una discapacidad; por ejemplo: cuando nos sometemos a una cirugía, o por ahí hemos tenido una fisura o esguince como la doctora Olga María en el semestre pasado - entonces es ahí donde vemos la necesidad que la infraestructura de la sociedad adopte un diseño general, y déjame decirte Vanessa que me gusta mucho tu mensaje, sobre todo cuando tú me contabas que querías que se vea claramente que la persona con discapacidad, no es la víctima, ni el superhéroe, que solo es una persona y esa es su característica, es su virtud, su cualidad y sus defectos y virtudes deben ser tratados y conocidos por la sociedad.

\section{Abog. Vanessa Thorsen:}

Ese es el tema y definitivamente quería complementar lo que estabas contando, la discapacidad no es algo ajeno, no es que a mí nunca me va pasar, definitivamente como bien contábamos en cualquier momento de nuestra vida hasta una gripe suele impedir a una persona expresarse. La discapacidad no es algo ajeno, ni es un premio, ni un castigo, es simplemente 
una condición, una característica y entonces tenemos que ver eso; y las personas con discapacidad, efectivamente, somos personas como cualquier persona con sentimientos, pensamientos, habilidades diferentes y lo único que buscamos es contribuir de la misma forma que las demás personas al desarrollo del Perú.

Es un tema de cambio de perspectiva, de mentalidad, y por qué no, afirmar, de la construcción de una cultura sustentada por cierto en la igualdad, que permita vernos como ciudadanos, con los mismos derechos y posibilidades de realizar nuestras aspiraciones, de dejar de vernos como los unos y los otros. Somos un todo, una Nación en la que todos debermos reconocernos como peruanos, todos somos parte de la sociedad y queremos lo mejor para ella, para que nuestros hijos y las futuras generaciones encuentren mejores condiciones para su desarrollo.

\section{Abog. Úrsula Bazán:}

Así es! Empoderarse y ver que todos somos iguales, que finalmente estamos hechos de lo mismo y como tu dijiste: "SIEMPRE PARA ADELANTE; NI DE RETROCESO NI SIQUIERA PARA EL IMPULSO".

Muchas gracias Vanessa y muchas gracias a ustedes. (Aplausos) 